\title{
Is using ICT at home good or bad for learning? A cross-country comparison of the impact of home use of ICT for entertainment and learning on PISA 2015 Science test results
}

\author{
Adrian Hatos \\ University of Oradea \\ ahatos@gmail.com
}

\begin{abstract}
There is much contradiction in the results of recent research results concerning the impact of ICT home use by students on learning. Despite the availability of the large body of data from the PISA 2015 survey in which respondents from 47 countries answered the ICT use modules, the research results are still far from conclusive either. Consequently, the purpose of the present research is to explore the cross-country variation of the impact of ICT use at home for entertainment and for learning on the Science test results obtained by students in PISA 2015. More specifically, linear regression models of PISA 2015 Science test results at country-level will be ran, then the variations in betas of the regression models for the 47 countries will be statistically investigated including correlations with other presumably important country-level descriptors. The main conclusions are that is erroneous to expect for positive or negative general effects, as most probably they depend on country-level features, and that the impact of home use, for learning and for entertainment respectively, of ICT are in a kind of homeopathic negative cross-country relationship.
\end{abstract}

Keywords: ICT impact on education, cross-country comparison, PISA 2015 Science results

\section{Introduction}

There is has been much excitement surrounding the potential of ICT with regard to enhancing academic achievement in formal education. ICT (Information and Communications Technology) can be used as a tool in formal education transforming regular educational practice in what is called Computer Assisted Instruction (CAI) which require certain infrastructure and skills, both from students and teachers. Moreover ICT is not also a mean or a medium but part of the curriculum and generator of skills as the world plunges into the $4^{\text {th }}$ Industrial Revolution. 
More troubling is the fact that, as we will show in the literature review, although there have been published numerous assessments regarding the impact of ICT on educational achievement and the data available for replicating the studies is getting larger with every year, the results are hardly conclusive. Even more, if one is to think of simple and concrete effects, say those of ICT use for entertainment or of using ICT at home to learn as is the case in the present paper, the results obtained with samples from different countries are everything but not convergent. Since the cross-country comparisons of the effects of ICT at home on learning are either rare, or involving a small number of countries or population weighted international data when using large international surveys (see PISA 2015) the purpose of the present research is to explore the cross-country variation of the impact of ICT use at home for entertainment and for learning on the Science test results obtained by student in PISA 2015. More specifically, linear regression models of PISA 2015 Science test results at country-level will be ran, then the variations in standardized regression parameters (betas) of the regression models for the 47 countries will be statistically investigated including correlations with other important country-level descriptors.

\section{Literature review}

On has to be aware that meta-analyzes in this field are difficult as one has to distinguish among various forms of ICT use that have been put to test in the particular researches concerned. For example, one has not to confuse digitalization of education which occurs at school with home use of ICT by students themselves. Another difference that have to be kept in mind is, when referring to home use, between ICT use for entertainment as compared to instrumental use, for learning. Our research will focus on cross-country variation of effect of home use of ICT for learning and for entertainment respectively controlling for socio-economic factor, gender and home availability of ICT technology.

\section{The impact of ICT on learning}

Concerning the effect of ICT use on academic achievement the research experience which is available is at best contradictory. Several research results concerning school use will be presented then the presentation will be funneled to results concerning the effects of home use of ICT.

\section{School use of ICT}

Even concerning the use of ICT in schools the results are non-conclusive as the current state of knowledge is synthesized in Skryabin et al (2015): positive but small to moderate impacts or the increasingly popular hypothesis that between ICT use and learning outcomes the relationship is inverse $U$-shaped and thus average and high intensity users would not gain from additional ICT use (Rodrigues \& Biagi, 2017).

A meta-analysis of 42 studies (1970-1999) comparing computer-assisted instruction to traditional instruction revealed that the computer-assisted teaching environment outperformed the traditional one generally (Bayraktar, 2001) while Torgerson and Zhu (2003) reported mixed evidence in their systematic literature review on the effectiveness of ICT in literacy learning (ages 5-16 years). Banerjee et al. On the other hand found that a computer-assisted learning programme for mathematical skills reinforcement showed a large and positive impact on achievement in mathematics as well (Banerjee, Cole, Duflo, \& Linden, 2007). On the negative side, a surprising result of the TIMSS 1995 survey is that 
computer use in the classroom was negatively associated with high student achievement in a number of countries (Papanastasiou, 2002).

More recent evaluations of programs of digitalization of education deliver positive results. Assessments of effects of blended learning environments is, for instance, usually positive. (Demirer \& Sahin, 2013; Kazu \& Demirkol, 2014). 2) Laptop programmes have been found to have positive effects: Zheng, B., et al. (2016) meta-analyzed 10 studies examining the impact of laptop programs on students' academic achievement and found significant positive effects in fields like English, writing, mathematics, and science. Rashid (2016) i.e. showed that use of ICT has a (presumably) direct positive relationship with students' engagement and self-directed learning, whereas no significant direct effect was found between technology use and academic performance.

\section{Home use of ICT}

When home use of ICT is concerned, the scorecard of the assessment of impact on education results is more troubling. Evaluation of net effect on achievement of introduction of home computers is found to find a decline in math and science achievement in US (Vigdor, Ladd, \& Martinez, 2014). PISA 2012 and 2015 (OECD, 2015) provide mixed if not entirely pessimistic view on the impact of use of computers and internet at home or at school on achievement in all three areas (maths, sciences and language) (Papanastasiou, 2002).

According to current research, digitalization in home learning activities, sometimes enthusiastically adopted, seem to have unexpected detrimental impact on education. Online learning is found usually to have lower educational effectiveness than offline learning (Coates, Humphreys, Kane, \& Vachris, 2004). Time spent on internet for other purposes than educational (Kim, Kim, Park, Kim, \& Choi, 2017) appears also as having a negative effect. Mobile devices/smartphones use in education bring many challenges too. Among them, the most salient are: distraction, dependency, lacking hands on skills, and the reduce quality of face-to-face interaction (Anshari, Almunawar, Shahrill, Wicaksono, \& Huda, 2017). Similarly, Lepp, Barkley, and Karpinski (2014) and Samaha and Hawi (2016) found that cell phone use/texting was negatively related to GPA and positively related to anxiety, stress and consequently negatively with satisfaction with life. This negative result was replicated in Portugal by Belo, Ferreira and Telang (2013)

The introduction of ICT domain related items in the latest rounds of PISA surveys (from 2009 on) had made available a large array of data to investigate the impact of home and school use of ICT for learning or for entertainment on the maths, reading and science skills of 15 years olds in tens of countries around the world. Some research using these data highlight the positive impact of ICT use on academic results (ref) while others pinpoint to opposite conclusions or to weak connection between ICT use and academic achievement. Biagi, F., \& Loi, M. (2013), using PISA 2009 data, concluded that achievement correlated positively with the number of ICT activities, not with the intensity of ICT use. On the contradictory results side Gómez-Fernández, N., \& Mediavilla, M. (2018) modelled the impact of home school and entertainment use of ICT in Spain upon PISA 2015 results and found that while the use for entertainment of ICT has positive effects, the use for learning at home has a negative impact.

This is likewise even with regards to the research results based on similar sets of data. For example, the research articles based on PISA 2015 and similar data which interrogate the relationships between ICT use and academic achievement hardly deliver 
conclusive results (Castellanos \& Martha, 2015; C. Hu, 2017; Juhaňák, Zounek, Záleská, Bárta, \& Vlčková, 2018; OECD, 2015; Saal, van Ryneveld, \& Graham, 2019; Srijamdee \& Pholphirul, 2020). One limit of these researches is that most of the investigations using these data are either at country level or attempt cross country comparisons employing data from a limited number of countries. Investigations using all the data in multilevel regressions are rather rare, and employ simple specifications which are constrained by the complicated data structures.

For example, Biagi and Loi (2013) found, analyzing the PISA 2009 data for 23 countries, that using ICT for entertainment has positive effect on test scores while using ICT for tasks more related to education has negative impact. An almost identical result was obtained with the PISA 2015 data from Spain, by Gomez-Fernandez \& Mediavilla (2018). But the same data set used to assess the effect of ICT use, availability and comfort on the science test score in Bulgaria and Finland revealed the ICT use and availability had in both countries negative impact (Odell, Galovan, \& Cutumisu, 2020). These results replicated in a certain degree those obtained by Bulut \& Cutumisu (2017) which compared PISA 2015 data from Finland with those from Turkey. They concluded that the availability of ICT at home and at school was positively associated with achievement in Turkey, but not in Finland. And, the use of ICT for entertainment was associated positively with achievement in Turkey, but negatively in Finland.

An attempt at solving the conundrum has been provided by Hu X \& al. (2018) who were the only ones so far, to our knowledge, to pool the entire 44 country PISA 2015 database containing the ICT items weighted at population level in order to assess definitively the causal relationships that interest us using multilevel regression. Among other results, they have concluded that student ICT academic use negatively correlated with student performance, while ICT entertainment use positively correlated with student performance.

It is obvious that the results of pooled data multilevel regressions of Hu \& al. (idem) contradicts some of the previous results obtained at country level. While country-level regressions repeatedly established that ICT use for entertainment has detrimental effect in Finland, the pooled data regression established a parameter of contrary sign. This might be explained simply because the Hu \& al.'s multilevel regressions pooled the population weighted PISA 2015 sample making the impact of larger populations to count more in the final parameter estimates. However, Hu \& al.'s article limits itself to simple fixed effects and does not test for the random variance of parameters as well as for the possible cross-level interactions affecting the fixed effects. This is an important shortcoming as the ICC test for the science scores show that between country variation accounts for $24 \%$ of the total variance.

Our point in this article is not contradicting Hu \& al's article but to contribute in revealing in a clearer way the impact of ICT use on student competencies. Inspired by the above mentioned results, and the contradictions among them, our opinion is that countrylevel variation and covariation in these effects is of larger significance than that implied in $\mathrm{Hu}$ \& al multilevel model. Therefore, in this article we will explore these relationships by assessing them not by using multilevel regressions but through country-level linear regressions and running a correlational analysis of cross-country covariations of standardized regressions parameters.

\section{Data and methods}


In order to explore the impact of use of ICT outside of school on school achievements the data from 47 countries participating in PISA2015 were used. In these 47 participating countries were collected responses to all the ICT use items included in the research. Data on the Chinese administrative regions participating in the PISA 2015 survey were excluded (except for Macao and Hong-Kong) as data on GDP for each is not available. Senate weights were used i.e. for each country the sample was made to be representative of the structure of the original population.

Dependent variables in our models were the PISA science test scores. As the PISA 2015 provided 10 plausible values for each student, we have run separate regressions for each plausible value and the parameters published here are the averages computed across the 10 regressions.

\section{Independent variables}

There were three focal variables: Index of home ICT resources (ICTRES), which I expect to determine ICT use outside of school for schoolwork (Homesch) and ICT use outside of school for leisure (Entuse).

Table 1. Variables in the regressions

\begin{tabular}{|l|l|}
\hline Name of variable & Measurement, Description \\
\hline Gender & Dichotomy: 0=male, 1=female \\
\hline ESCS & Scale: Index of family socio-economic status \\
\hline ICTRES & Scale: Index of Home ICT resources (WLE) \\
\hline Homesch & Scale: Index of ICT use outside of school for schoolwork \\
\hline Entuse & Scale: ICT use outside of school for leisure \\
\hline
\end{tabular}

The description of all indexes used in the analyzes, including the items and the measurement properties, can be found in the PISA2015 Technical Report - especially in Chapter 16 (http://www.oecd.org/pisa/sitedocument/PISA-2015-Technical-Report-Chapter-16Procedures-and-Construct-Validation-of-Context-Questionnaire-Data.pdf)

\section{Procedure}

Linear regressions of plausible values for the science test were run for each of the 47 countries and territories. For each of the beta parameters the average across the 10 regressions were computed. To the table of average beta parameters we have added the country level science PISA average, the country-level GDP per capita and Gini index for 2014 or before. ${ }^{1}$

\section{Results}

There is a large variation in explanatory capacity of the 47 regressions, ranging from Adjusted R-square of 0.018 (Macao) to 0,249 (Hungary). That is, the explanatory power of our models range from almost nil to a quarter of the total variance. There is also a great cross-country variation of parameters.

\footnotetext{
${ }^{1}$ Source of GDP/capita and Gini data: https://databank.worldbank.org/home.aspx
} 
Table 2. Parameter averages, minimums and maximums (47 countries, 470 regressions)

\begin{tabular}{|l|r|r|r|}
\hline & Mean & Minimum & Maximum \\
\hline Adjusted R Square & 0,156 & 0,019 & 0,249 \\
\hline Gender & $-0,038$ & $-0,134$ & 0,068 \\
\hline ICTRES & 0,005 & $-0,114$ & 0,260 \\
\hline HOMESCH & $-0,104$ & $-0,229$ & 0,111 \\
\hline ENTUSE & 0,005 & $-0,135$ & 0,152 \\
\hline ESCS & 0,354 & 0,142 & 0,485 \\
\hline
\end{tabular}

Regarding the betas, there is only one parameter that has consistent effect across the globe: ESCS. Regardless of country, the higher is one student's family placed on the socio-economic ladder the better he/she performed in science test. For the other 4 parameters we have variations in sign also. For example, boys have usually an advantage, with the largest being recorded in Austria and Croatia but countries like Uruguay, France and Chile show a small positive effect for girls. The effects in the case of our focal variables - ICT availability and ICT use for school and entertainment at home display, though, a much larger variability. All the largest estimates are significant at the $5 \%$ threshold. ICT home use for entertainment has a negative effect in roughly half the investigated countries (20) while in the rest the parameter is positive. The largest positive effect of using ICT for fun we record in Costa Rica, Chile and Poland while the largest negative impact in places like Colombia, UK and Australia. Learning with ITC is more consistently negatively correlated with the science score, although in Colombia and Korea the effect is significantly positive.

\section{Country-level correlations of parameters}

Table 3. Country-level correlations (47 countries except for Gini were there are only 42 countries)

\begin{tabular}{|l|c|c|c|c|c|c|c|c|}
\hline & Gender & ICTRES & HOMESCH & ENTUSE & ESCS & GDPcapita2018 & $\begin{array}{l}\text { PISA2015 } \\
\text { Science }\end{array}$ & Gini 2014 \\
\hline Gender & 1 & 0,008 & $-0,161$ & $0,426^{* *}$ & $-0,372^{*}$ & $-0,089$ & $-0,133$ & 0,23 \\
\hline ICTRES & 0,008 & 1 & 0,049 & 0,267 & $-0,543^{* *}$ & $-0,355^{*}$ & $-0,138$ & 0,105 \\
\hline HOMESCH & $-0,161$ & 0,049 & 1 & $-0,662^{* *}$ & $-0,241$ & $-0,203$ & $-0,198$ & 0,138 \\
\hline ENTUSE & $0,426^{* *}$ & 0,267 & $-0,662^{* *}$ & 1 & $-0,255$ & 0,002 & 0,096 & 0,049 \\
\hline ESCS & $-0,372^{*}$ & $-0,543^{* *}$ & $-0,241$ & $-0,255$ & 1 & $0,345^{*}$ & 0,206 & $-0,279$ \\
\hline GDPcapita2018 & $-0,089$ & $-0,355^{*}$ & $-0,203$ & 0,002 & $0,345^{*}$ & 1 & $0,527^{* *}$ & $-0,508^{* *}$ \\
\hline $\begin{array}{l}\text { PISA2015 } \\
\text { Science }\end{array}$ & $-0,133$ & $-0,138$ & $-0,198$ & 0,096 & 0,206 & $0,527^{* *}$ & 1 & $-0,729^{* *}$ \\
\hline Gini 2014 & 0,230 & 0,105 & 0,138 & 0,049 & $-0,279$ & $-0,508^{* *}$ & $-0,729^{* *}$ & 1 \\
\hline
\end{tabular}

** Correlation is significant at the 0.01 level (2-tailed).

* Correlation is significant at the 0.05 level (2-tailed).

It is striking how clearly negative the cross-country correlation of the effects of school related and entertainment related use of ICT are. At the country level the two measures run in contrary directions with so much strength that one can explain almost half the variation $(44 \%)$ in one though the variation of the other parameter. Actually, there is only one country in which both variables have positive sign, Mexico, where both parameters are in fact nonsignificant. This is the result of a negative predominance for betas of both variables which is described by the trendline which intersects the axes well below the origin. 


\section{ENTUSE}

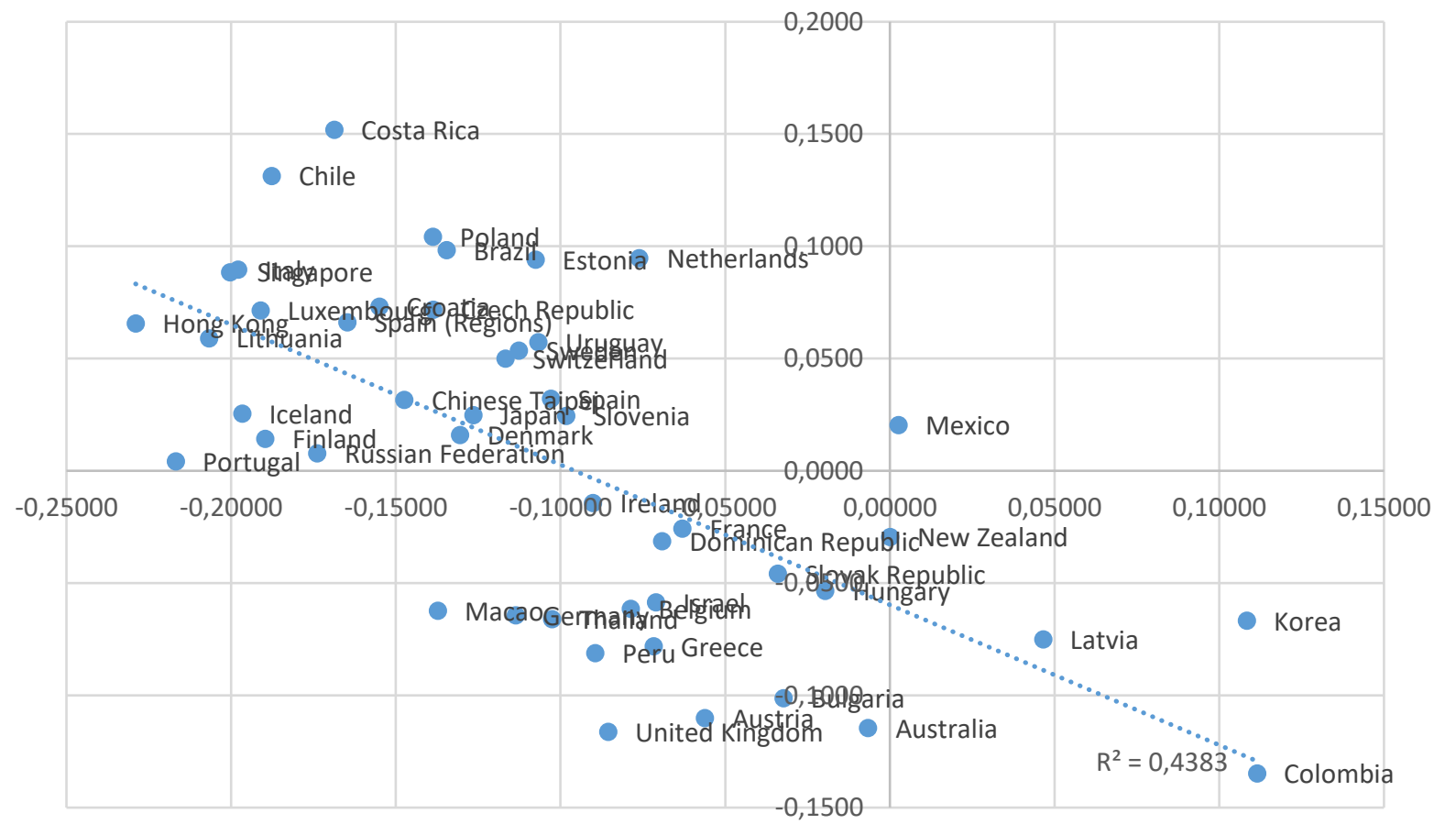

Figure 1. ICT at home for school (X) vs ICT for entertainment $(Y)$

It is interesting that while the betas of ICT school related use correlate only with the entertainment use betas, the latter has also a strong positive correlation with the gender betas. In other words, the larger the girl advantage the stronger positive is the effect of ICT use for entertainment or, put in reverse terms, the smaller the girl advantage the smaller the impact of entertainment use. It is also relevant that none of the three ICT- related variables (betas of linear regressions done in each country) correlate with the fundamental economic descriptors - GDP/capita and Gini coefficient.

On the other hand, the country level parameter of gender correlates negatively with the similar parameter of ESCS meaning that the larger the girl effect in acquiring science competencies the smaller the impact of socio-economic status on the same variable. This translates into the rather well-known conclusion that the larger the socio-economic gradients - effects of social and economic background of the family, the more important is being male in obtaining good educational achievement. Boys have an advantage in acquiring Science skills when economic inequality has a larger impact on education results.

Betas of availability of ICT resources of home though do not correlate with the two ICT home use variables but they do so negatively with ESCS and with GDP/capita. The larger the effect of one's socio-economic background or the GDP/capita in a country, the smaller the impact the availability of ICT resources at home. 


\section{ENTUSE}

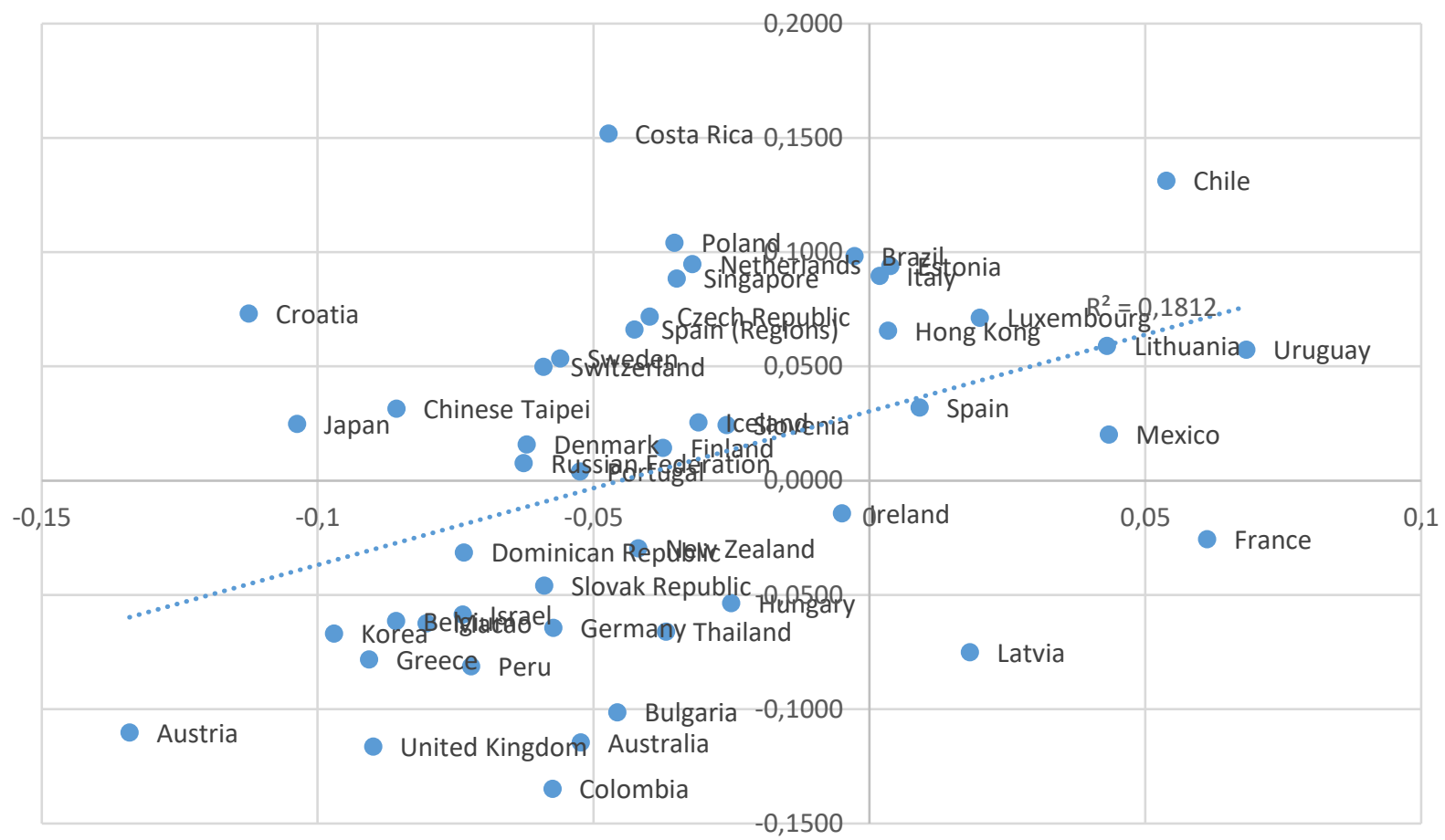

Figure 2. Betas of gender (X) against Betas of ICT use for entertainment

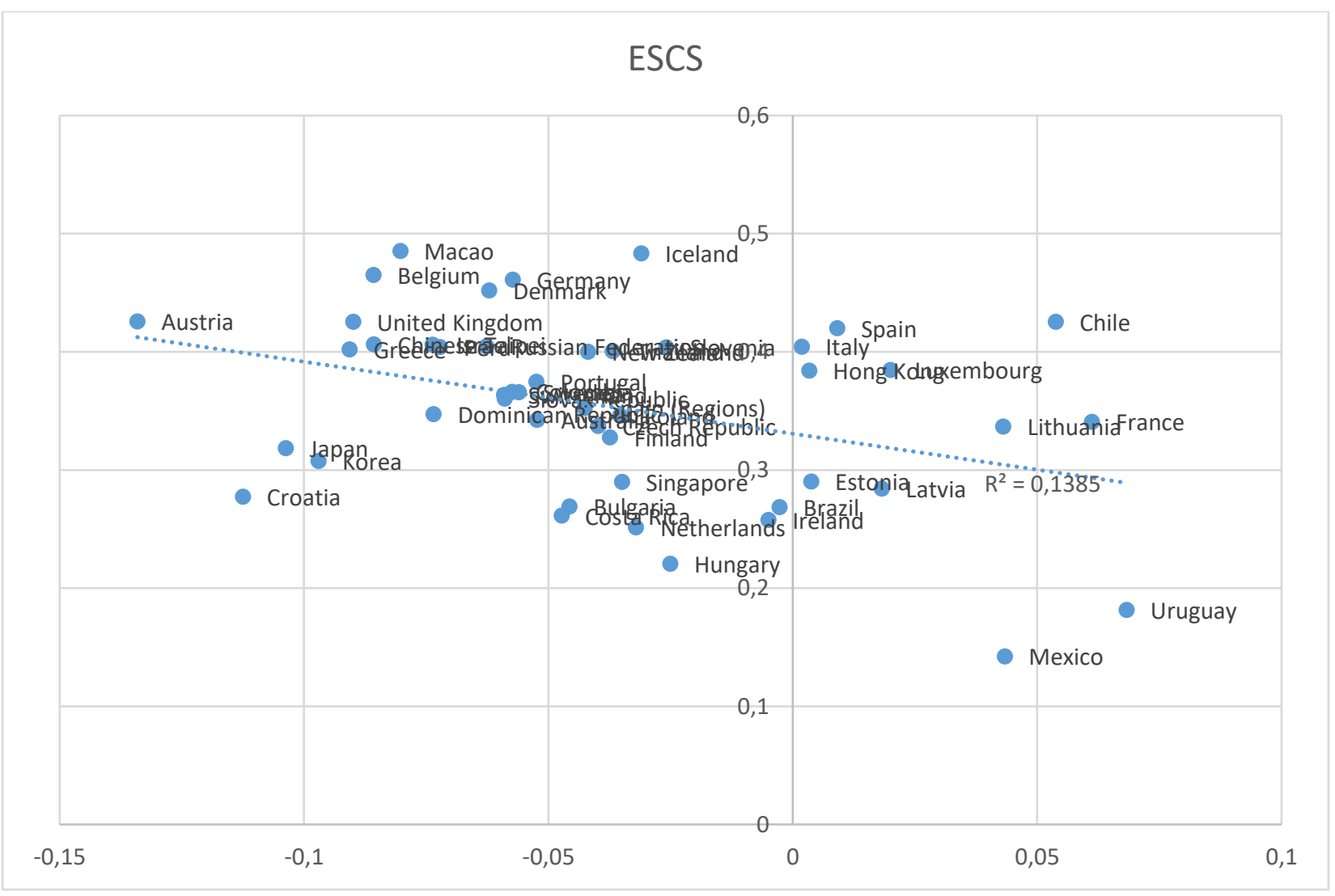

Figure 3. Betas of Gender ( $x$ ) against betas for ESCS (y) 


\section{Discussions}

Our country-level correlational analysis of standardized parameters of regressions of PISA 2015 science tests results against ICT use at home and ICT resources availability at home provided some very interesting results. Most important among them is the strong negative correlation of the country-level impact of home use of ICT for entertainment and for school respectively. The intensity of the correlation suggests that the individual level impact of the two independent focal variables have a rather country-level determination. This means on the one hand that the effect of types of home use of ICT is to be explained by features of the socio-economic or institutional system of the country as a whole and, moreover, they are at nation-level in a kind of homeopathic relationship which almost forbids that both of them have positive effect in the same time.

Our correlations do little to enlighten the relationship between the two variables the country level betas of the linear regressions of Science test results. We can merely notice that the variation of beta of entertainment home use appears to be exogenously determined, via the correlations with the beta of gender (positive with girl advantage) which in its turn has a strong correlation with the impact of ECSC (negative with girl advantage). It is apparent thus that the expected positive impact of home learning using ICT depends on the socio-economic structure of the country, measured by distributional variables like GDP/capita, socio-economic gradient and gender imbalance in educational advantage regarding skills acquisition which determines how the measure in which using ICT affects the results of learning.

\section{Limits}

The above results have all the limits of correlations between aggregated values while the variable to be explained is at individual level. Ecological error may bias inferences about factors of individual achievement based on country-level data. Our correlations just hint at possible relationships at individual level which can be confounded with relationships at upper levels or with interactions across levels. In any case further research should be don employing multilevel regression that takes into account the relationships suggested in the present research and includes also other controls that could account for the two-way covariations we have revealed.

\section{Conclusions}

The main conclusion of the present exploratory research is that, most probably, ICT use for entertainment or learning at home are neither good nor bad for academic achievement but the impact depends on the country in which one makes the assessment. In other words, there are countries in which learning using ICT has negative effect on the efficacy of learning while there are education systems in which this effect is positive. The cross country comparison suggests a dominance of negative effects for both variables though.

A second important result is that at country-level the educational effect of the two variables measuring the use ICT at home for learning or for entertainment are in a negative relationship - the more positive is the effect of one the negative is the individual effect of the other.

Moreover, the strong country level negative correlation of betas of the two focal variables of ICT home use suggest that one has to look for the explanation of the situation in which one country find itself from this point of view also among variables at the country level. It is hard to imply from that one is determined directly by the value of the other and 
further research is needed to reveal the social, economic, cultural or institutional features of countries that commonly determine or mediate the correlations revealed here. These future researches should integrate the hypotheses suggested here in well specified multilevel regression models.

\section{References}

Anshari, M., Almunawar, M. N., Shahrill, M., Wicaksono, D. K., \& Huda, M. (2017). Smartphones usage in the classrooms: Learning aid or interference? Education and Information Technologies, 22(6), 3063-3079.

Banerjee, A. V., Cole, S., Duflo, E., \& Linden, L. (2007). Remedying education: Evidence from two randomized experiments in India. The Quarterly Journal of Economics, 122(3), $1235-1264$.

Bayraktar, S. (2001). A meta-analysis of the effectiveness of computer-assisted instruction in science education. Journal of Research on Technology in Education, 34(2), 173-188.

Belo, R., Ferreira, P., \& Telang, R. (2013). Broadband in school: Impact on student performance. Management Science, 60(2), 265-282.

Biagi, F., \& Loi, M. (2013). Measuring ICT use and learning outcomes: Evidence from recent econometric studies. European Journal of Education, 48(1), 28-42.

Bulut, O., \& Cutumisu, M. (2017). When technology does not add up: ICT use negatively predicts mathematics and science achievement for Finnish and Turkish students in PISA 2012. Paper presented at the EdMedia+ Innovate Learning.

Castellanos, S., \& Martha, P. (2015). ¿ Son las TIC realmente, una herramienta valiosa para fomentar la calidad de la educación? Retrieved from http://repositorio.minedu.gob.pe/bitstream/handle/123456789/4516/Son\%20las\%2 0TIC\%20realmente\%2C\%20una\%20herramienta\%20valiosa\%20para\%20fomentar\%2 0la\%20calidad\%20de\%20la\%20educación.pdf?sequence=1\&isAllowed=y

Coates, D., Humphreys, B. R., Kane, J., \& Vachris, M. A. (2004). "No significant distance” between face-to-face and online instruction: Evidence from principles of economics. Economics of Education Review, 23(5), 533-546.

Demirer, V., \& Sahin, I. (2013). Effect of blended learning environment on transfer of learning: An experimental study. Journal of Computer Assisted Learning, 29(6), 518529.

Gómez-Fernández, N., \& Mediavilla, M. (2018). Do information and communication technologies (ICT) improve educational outcomes? Evidence for Spain in PISA 2015. Retrieved from: http://diposit.ub.edu/dspace/bitstream/2445/126961/1/IEB1820_Gomez\%2BMediavilla.pdf

$\mathrm{Hu}, \mathrm{C} .(2017)$. Students, computers and learning: Where is the connection? Education Information Technologies, 22(6), 2665-2670.

Hu, X., Gong, Y., Lai, C., \& Leung, F. K. (2018). The relationship between ICT and student literacy in mathematics, reading, and science across 44 countries: A multilevel analysis. Computers \& Education, 125, 1-13.

Juhaňák, L., Zounek, J., Záleská, K., Bárta, O., \& Vlčková, K. (2018). The Relationship between Students' ICT Use and Their School Performance: Evidence from PISA 2015 in the Czech Republic. Orbis scholae, 12(2). 
Kazu, I. Y., \& Demirkol, M. (2014). Effect of blended learning environment model on high school students' academic achievement. TOJET: The Turkish Online Journal of Educational Technology, 13(1).

Kim, S. Y., Kim, M.-S., Park, B., Kim, J.-H., \& Choi, H. G. (2017). The associations between internet use time and school performance among Korean adolescents differ according to the purpose of internet use. PloS one, 12(4), e0174878.

Lepp, A., Barkley, J. E., \& Karpinski, A. C. (2014). The relationship between cell phone use, academic performance, anxiety, and satisfaction with life in college students. Computers in human behavior, 31, 343-350.

Odell, B., Galovan, A. M., \& Cutumisu, M. (2020). The Relation Between ICT and Science in PISA 2015 for Bulgarian and Finnish Students. EURASIA Journal of Mathematics, Science Technology Education, 16(6), em1846.

OECD. (2015). Students, computers and learning: Making the connection. Retrieved from http://www.oecd.org/publications/students-computers-and-learning9789264239555-en.htm

Papanastasiou, E. (2002). Factors that differentiate mathematics students in Cyprus, Hong Kong, and the USA. Educational Research and Evaluation, 8(1), 129-146.

Rashid, T., \& Asghar, H. M. (2016). Technology use, self-directed learning, student engagement and academic performance: Examining the interrelations. Computers in human behavior, 63, 604-612.

Rodrigues, M., \& Biagi, F. (2017). Digital technologies and learning outcomes of students from low socio-economic background: An Analysis of PISA 2015. Retrieved from Luxembourg:

http://publications.jrc.ec.europa.eu/repository/bitstream/JRC106999/jrc106999_eff ectiveedu_wp4_final.pdf

Saal, P. E., van Ryneveld, L., \& Graham, M. A. (2019). The Relationship between Using Information and Communication Technology in Education and the Mathematics Achievement of Students. International Journal of Instruction, 12(3), 405-424.

Samaha, M., \& Hawi, N. S. (2016). Relationships among smartphone addiction, stress, academic performance, and satisfaction with life. Computers in human behavior, 57 , 321-325.

Skryabin, M., Zhang, J., Liu, L., \& Zhang, D. (2015). How the ICT development level and usage influence student achievement in reading, mathematics, and science. Computers \& Education, 85, 49-58.

Srijamdee, K., \& Pholphirul, P. (2020). Does ICT familiarity always help promote educational outcomes? Empirical evidence from PISA-Thailand. Education Information Technologies, 1-38.

Torgerson, C., \& Zhu, D. (2003). A systematic review and meta-analysis of the effectiveness of ICT on literacy learning in English, 5-16: EPPI-Centre, Social Science Research Unit, Institute of Education, University of London.

Vigdor, J. L., Ladd, H. F., \& Martinez, E. (2014). Scaling the digital divide: Home computer technology and student achievement. Economic Inquiry, 52(3), 1103-1119.

Zheng, B., Warschauer, M., Lin, C.-H., \& Chang, C. (2016). Learning in one-to-one laptop environments: A meta-analysis and research synthesis. Review of Educational Research, 86(4), 1052-1084. 